\title{
Validity and reliability of the Farsi version of Wijma delivery expectancy questionnaire: an exploratory and confirmatory factor analysis
}

\author{
Forough Mortazavi
}

Ph.D. of Reproductive Health, Assistant Professor, Department of Midwifery, Faculty of Nursing \& Midwifery, Sabzevar University of Medical Sciences, Sabzevar, Iran

\section{Type of article: Original}

\begin{abstract}
Background: Fear of childbirth may cause complications such as experiencing severe labour pain, postpartum depression, and impaired mother-fetus attachment.

Objective: To validate the Farsi version of the Wijma Delivery Expectancy/Experience Questionnaire (W-DEQ) (versions A \& B) in a sample of Iranian women.

Methods: The WDE-Q (versions A \& B) was translated into Farsi, and the content validity of the scales was confirmed. In a cross-sectional study conducted in 2015, 405 pregnant women in the third trimester of pregnancy and 320 postpartum women completed the Farsi W-DEQ versions A \& B, respectively. The construct validity and reliability of the scales were examined using exploratory and confirmatory factor analyses (EFA and CFA) and Cronbach's alpha coefficient, respectively. SPSS version 18 and Lisrel version 8.80 were used for statistical analyses.

Results: Results of the CFA on 33 items could not confirm the one-factor structure proposed by Wijma (RMSEA $=0.14, \mathrm{SRMR}=0.11$, Chi-square $/ \mathrm{df}=8.95, \mathrm{p}<0.05, \mathrm{CFI}=0.86, \mathrm{IFI}=0.86$ ) or other structures suggested by previous studies. We conducted an EFA on 33-item version A and found six factors with eigenvalue $>1$. One item was not loaded on any factor. A CFA on 32 items of the W-DEQ (version B) yielded acceptable fit for the factorial structure found on version A (RMSEA $=0.075$ (CI [0.071, 0.08]), SRMR=0.078, Chi-square/df $=2.93$, $\mathrm{p}<0.05, \mathrm{CFI}=0.95$, IFI=0.95). Cronbach's Alpha coefficients for the 32-item Farsi W-DEQ (versions A \& B) were 0.914 and 0.919 , respectively.

Conclusions: Both Farsi W-DEQ are reliable and valid instruments to assess fear of childbirth in Iranian pregnant and postpartum women. Further research should be designed to examine the validity of the W-DEQ (A) in pregnant women regardless of gestational age.

Keywords: Fear, Anxiety, Childbirth, Parturition, Psychometric, Postpartum
\end{abstract}

\section{Introduction}

Pregnancy and giving birth to a child are two of the most significant, fantastic, and pleasant events in most women's lives. However, for some women, these events are stressful and may be associated with severe fear of childbirth. Receiving support from partner and family and counselors may decrease unusual fear of childbirth. If untreated, fear of childbirth remains and increases with approaching labor onset (1). According to previous studies, $20 \%$ of women experience severe anxiety and fear of childbirth. Severe fear of childbirth may interfere with the daily life of $6 \%$ to $10 \%$ of women (2). Studies indicated that fear of childbirth is multidimensional and can be categorized into domains including pain, obstetric injuries, loneliness, loss of control, insufficient support, and loss of the baby's or the mother's life $(2,3)$. Childbirth fear may cause complications such as experiencing severe labor pain (4), postpartum depression or anxiety, physical problems, and impaired mother-fetus attachment (5-7). Anxiety and stress can increase the levels of catecholamine, which can decrease uterine contraction and prolong labor duration $(8,9)$. It is also reported that the rate of both elective and urgent Cesarean increased as fear of childbirth increased $(10,11)$. One

\section{Corresponding author:}

Dr. Forough Mortazavi. Department of Midwifery, Faculty of Nursing \& Midwifery, Sabzevar University of Medical Sciences, Sabzevar, Iran. Tel: +98.9151737039, Fax: +98.5144445648, Email: frmortazavi@yahoo.com Received: April 22, 2016, Accepted: September 02, 2016, Published: June 2017 iThenticate screening: July 31, 2016, English editing: October 19, 2016, Quality control: January 17, 2017 (C) 2017 The Authors. This is an open access article under the terms of the Creative Commons Attribution-NonCommercialNoDerivs License, which permits use and distribution in any medium, provided the original work is properly cited, the use is non-commercial and no modifications or adaptations are made. 
of the negative consequences of childbirth fear is the growing demand for cesarean (12). Maternal requests for Cesarean has risen in recent decades. The rates were $6.4 \%$ in Australia (13), 8.2\% in Sweden, and 7\% in the United Kingdom $(14,15)$. Iran was ranked as the second country in the world with the highest Cesarean rate $(42 \%)$ in 2010 (16). In a study in Iran, Tehran, the rate of elective Cesarean was $72 \%$ of which $22 \%$ was done due to maternal request (17). It seems that maternal requests for Cesarean in Iran are more than twofold the rate in developed countries. It is, therefore, important to screen pregnant women for fear of childbirth to design interventions for making childbirth a pleasant event in a woman's life. For the task of screening and care of childbearing women, it is necessary to validate a scale to measure and quantify childbirth fear. The Wijma Delivery Expectancy/Experience Questionnaire (W-DEQ) is the most commonly used scale to measure different aspects of childbirth fear. The scale was designed by Wijma in late 1980 and included two versions for assessing childbirth fear during pregnancy (version A) and after childbirth (version B) (18). The scales were designed to measure different dimensions of childbirth fear, though it was ideated as a one-dimensional instrument. Thus far, the W-DEQ scales has not been either translated into Farsi or validated in Iran. Therefore, this study was conducted to translate the scales into Farsi and validate and investigate the factor structure of the Farsi W-DEQ versions A \& B in Iranian women. Lack of such instruments has been led to poor knowledge about psychological aspects of childbirth in an eastern country such as Iran.

\section{Material and Methods}

\subsection{Research design, settings, and sampling}

This cross-sectional study was conducted in two phases. In the first phase, 405 pregnant women registered at eight public health clinics affiliated with Sabzevar University of Medical Sciences participated in the validation of the Farsi W-DEQ version A. Sampling was done in Sabzevar City in Iran from January to June 2015. The inclusion criteria were as follows: having the ability to read and being in the third trimester of pregnancy with no indication for cesarean. In the second phase, 320 women at two weeks postpartum were included for the validation of the Farsi W-DEQ version B. The inclusion criteria for the study second phase were as follows: having the ability to read, giving birth vaginally, and being at two weeks postpartum.

\subsection{Data collection}

The city has 16 clinics, which cover the entire population. To select clinics, the city was divided into four regions. In each region, two clinics were randomly selected. In each clinic, all women who consented to participate in the study and met the inclusion criteria were enrolled. Women with a history of psychiatric disorders who were under medical care were excluded.

\subsection{Measurement tools}

\subsubsection{Childbirth Attitudes Questionnaire (CAQ)}

The Childbirth Attitudes Questionnaire (CAQ) was first created by Harman (19), but he did not examine the reliability and validity of the scale. Lowe revised the scale and demonstrated reliability and validity of the scale (3). The original version of the scale consisted of 16 items scored on a 4-point Likert scale ranging from 1 to 4 . Items began with "fear of" such as "fear of the baby being injured during childbirth," and "fear of being torn during childbirth." The internal consistency of the 16 items was good (Cronbach's alpha $=0.83$ ). The Farsi CAQ consisted of 14 items. Khorsandi supported the content validity of the Farsi CAQ. The internal consistency of the Farsi CAQ was good (Cronbach's alpha $=0.84)(20)$.

\subsubsection{The State-Trait Anxiety Inventory (STAI)}

The Spielberger State-Trait Anxiety Inventory (STAI) is composed of two inventories (21). The State Anxiety Inventory measures anxiety at the time of assessment, which can fluctuate over time. The Trait Anxiety Inventory measures anxiety level as a personal characteristic, which is stable over time. Each scale included 20 items with a response scale of 1-4. The scales' total score ranges from 20 to 80 , with higher scores indicating higher anxiety. The STAI showed good internal consistency (Cronbach's alpha $=0.89)(22)$. Mahram translated the scale into Farsi and confirmed the validity of the instrument. The internal consistency of the Farsi state (Cronbach's alpha $=0.91$ ) and trait (Cronbach's alpha $=0.90)$ items were excellent $(23)$.

\subsubsection{Edinburgh Postpartum Depression Scale (EPDS)}

The Edinburgh Postpartum Depression Scale (EPDS) was developed by Cox et al. (24) for use in postpartum women. It consisted of 10 items. Each item is rated on a 4-point Likert scale, yielding maximum scores of 30. The scale was translated into Farsi and validated. The Farsi EPDS discriminated well between women with caesarean and women with vaginal delivery (25). 


\subsubsection{Wijma Delivery Expectancy/Experience Questionnaires (W-DEQ)}

The Wijma Delivery Expectancy/Experience Questionnaires (W-DEQ), developed by Wijma, et al. (18), are two scales that measure a woman's prenatal perception of childbirth and her expectancy (version A) and her experience with the delivery (version B). Each contains 33 items that are rated on a 6-point Likert scale ranging from 0 (extremely) to 5 (not at all). The minimum and the maximum total scores of the questionnaires are 0 and 165 , respectively, with higher scores indicating higher fear. Validity and reliability of the scales were confirmed during the developmental processes. The internal consistency of the version A was excellent (Cronbach's alpha $=0.93$ ) (18). The internal consistency of the version B, which was administered at 2 hours (Cronbach's alpha $=0.93$ ) and five weeks postpartum (Cronbach's alpha $=0.94$ ) were excellent $(26)$. The validity of the version A and B were confirmed by moderate correlations between the scales and instruments such as the Beck Depression Inventory, Trait Spielberger Anxiety Inventory, Karolinska Scale of Personality, and S-R Inventory of Anxiousness (26), indicating that both versions were related to those scales while measured different psychological aspects. For both versions, the correlations between the scales and other instruments were higher in multiparas than nulliparous. They were translated into various languages including Italian, Turkish, and Japanese (27-30). The factorial structures of the scales were analyzed in previous studies (27-33).

\subsection{Process of translation and content validity}

\subsubsection{Process of translation}

Two specialists in English language and reproductive health translated both W-DEQ versions A\&B into Farsi. The final versions were back-translated into English. A bilingual Ph.D. with the help of the main researcher of the study compared the three versions. Few minor revisions were done.

\subsubsection{Content validity}

An expert panel consisted of four faculty members, who were specialists in reproductive health, gynecology, and midwifery discussed the wording and relevance of the scales' items for Iranian culture. Experts expressed their worry about the rating of items. To determine content validity ratio (CVR), we used the Lawshe method (34). The scale was sent to 10 experts in reproductive health, gynecologist, psychologist, and midwives who had worked in antenatal clinics or labor and delivery wards at least for 15 years to evaluate the items. They evaluated the necessity of the items using a 3-point rating scale: (1) not necessary; (2) useful, but not essential; (3) essential. No item had a CVR $<0.62$, indicating a satisfactory content validity. Subsequently, experts judged the clarity, simplicity, and relevancy of each item on a 4-point scale from not relevant, not simple, and not clear (1) to very relevant, very simple, and very clear (4). No item had a CVI less than 0.8 , recommended as acceptable CVI by 10 experts (35). In the pilot study, 20 low-educated pregnant women completed the Farsi W-DEQ. Some women were confused and stated that the questionnaire was difficult to rate. To solve the problem, the researcher substituted a sentence instead of a two-tailed phrase for each item except items 32 and 33; so that women could rate each item on a 6-point Likert scale ranging from 0 (completely agree) to 5 (completely disagree).

\subsection{Research ethics}

The Ethics Committee of Sabzevar University of Medical Sciences approved the study protocol (Approval No: Medsab.Rec.93.38). Permission to translate and use the W-DEQ was obtained from the author before the beginning of the study. Women were ensured that their information will be kept confidential. They had signed the informed consent form before they were instructed on how to complete the questionnaires.

\subsection{Statistical analysis}

Data analysis was performed by SPSS v. 18 and Lisrel v. 8.80. An Alpha Cronbach coefficient was used to investigate the reliability of the both versions of the Farsi WDE-Q. Alpha Cronbach values $>0.7$ were considered as acceptable (36). Exploratory factor analysis (EFA) was conducted to disclose the factorial structure of the Farsi WDE-Q version A. The extraction method was principal axis factoring with promax rotation because the data was not normally distributed. The criterion for retaining the items was item-loading $\geqslant 0.3$. Confirmatory factor analysis (CFA) was conducted to investigate the factorial structure of the Farsi WDE-Q version A proposed by other studies and to confirm the factorial structure of the version B proposed by the results of the EFA on the Farsi WDE-Q version A. The CFA was conducted via structural equation modeling. The model fit in the present study was considered acceptable if at least two of the following three criteria were met: a root mean square error of approximation (RMSEA) values $<0.08$, p-value $>0.05$, and relative Chi-square $<3(37,38)$. In addition, the following goodness-of-fit indices were also used to assess the model fit: normed fit index (NFI $>.90$ acceptable), the comparative fit index (CFI $>0.90$ acceptable), incremental fit index (IFI $>0.90$ acceptable), goodness of fit index (GFI $>0.90$ acceptable) $(39,40)$, and standardized root mean square residual (SRMR $<0.08$ acceptable) (41). An 
RMSEA value $\geq 1$ was considered as model misfit (40). Convergent validity of the scale was examined by calculating Spearman correlation coefficients between the Farsi W-DEQ (version A) and the Farsi CAQ. Concurrent validity was examined by calculating Spearman correlation coefficients between the Farsi W-DEQ (version A) and STAI as well as the Farsi W-DEQ (version B) and EPDS. For discriminant validity, a t-test was used to compare the Farsi W-DEQ (version B) scores of primiparous and multiparas. Also, the Farsi W-DEQ mean scores of women with low and high childbirth fear were compared. The median CAQ score of 37 was used as a cutoff point for childbirth fear in this study. Predictive validity was examined by comparing the Farsi W-DEQ (version A) mean scores of women who wished for Cesarean with women who did not. In addition, a t-test was used to compare the Farsi W-DEQ (version B) mean scores of women who preferred vaginal delivery for their next pregnancies with women who preferred cesarean.

\section{Results}

\subsection{Socio-demographic characteristics}

Characteristics of participants in ante- and postpartum phases of the study are presented in Table 1 . The mean and standard deviation of women's age were $26.3 \pm 5.1$ and $26.7 \pm 5.1$ years for ante- and postpartum, respectively. The average gestational age was $34.6 \pm 3.2$ weeks. More than half of women were primigravida $(58 \%)$, and $16.8 \%$ of women in antepartum phase reported a history of abortion.

Table1. Participants' characteristics

\begin{tabular}{|l|l|l|l|}
\hline Variables & Prenatal; $n(\%)$ & Postnatal; $n(\%)$ \\
\hline Age (years) & $<20$ & $33(8.3)$ & $20(6.3)$ \\
\cline { 2 - 4 } & $20-30$ & $280(70.4)$ & $231(72.2)$ \\
\cline { 2 - 4 } & $30<$ & $78(19.6)$ & $68(21.3)$ \\
\hline \multirow{4}{*}{ Educational level (years) } & $<6$ & $16(4)$ & $12(3.8)$ \\
\cline { 2 - 4 } & $6-12$ & $233(62)$ & $183(57.2)$ \\
\cline { 2 - 4 } & $\geq 12$ & $151(38)$ & $125(40)$ \\
\hline \multirow{5}{*}{ Job } & Homemaker & $340(85)$ & $270(84.4)$ \\
\cline { 2 - 4 } & Employed & $31(7.5)$ & $28(8.8)$ \\
\cline { 2 - 4 } & Self employed & $16(4)$ & $11(3.4)$ \\
\cline { 2 - 4 } & Student & $14(3.5)$ & $11(3.4)$ \\
\hline Parity & None & $234(58)$ & - \\
\cline { 2 - 4 } & One & $136(34)$ & $189(59.1)$ \\
\cline { 2 - 4 } & Two or more & $34(8)$ & $131(40.9)$ \\
\hline \multirow{2}{*}{ Desirability of pregnancy } & Yes & $279(70.3)$ & $240(75)$ \\
\cline { 2 - 4 } & No & $118(29.7)$ & $80(25)$ \\
\hline Income (million RIL) & $<10$ & $296(75)$ & $230(72.3)$ \\
\cline { 2 - 4 } & $10-20$ & $87(24.2)$ & $75(23.4)$ \\
\cline { 2 - 4 } & $>20$ & $14(3.6)$ & $13(4)$ \\
\hline
\end{tabular}

\subsection{Construct validity}

3.2.1. Confirmatory factor analysis (CFA)

Construct validity was assessed by conducting CFA on 33 items of the Farsi WDE-Q (version A). Results indicated that neither the uni-dimensional model proposed by Wijma nor four nor six-dimension structures found in previous studies provided a reasonable fit to our data. Because the number and content of items of the WDE-Q version A and $\mathrm{B}$ are the same, an EFA on the Farsi WDE-Q (version A) was conducted to find the structure of the Farsi WDE-Q version A. Subsequently, a CFA on the Farsi WDE-Q (version B) was conducted to investigate whether the structure yielded by the EFA fitted the postnatal data. Results of the CFA on the 32-items Farsi WDE-Q (version B) showed that the model yielded by the EFA on the Farsi WDE-Q (version A) fitted the postnatal data. In Table 2, results of the CFA based on structures proposed by different authors and the structure found in this study is presented. All factor loadings were 0.40 to 0.90 .

\subsubsection{Exploratory factor analysis (EFA)}

Because the structures found in previous studies did not fit our data, an EFA was used to disclose the factor structure of the Farsi WDE-Q version A. Kaiser-Meyer-Olkin measure of sampling adequacy was .904 and Bartlett's Test of Sphericity was $6669(\mathrm{p}<0.001)$, indicating adequate correlations between variables to do an EFA. One item (item1) was not loaded on any factor and was removed from the scale. The results of the EFA on the 32-item Farsi W-DEQ 
http://www.ephysician.ir

indicated six factors with eigenvalues $\geq$ one as follows: lack of self-efficacy, loneliness, fear, lack of positive anticipation, concerns for the child, and loss of control (Table 3). The factors' names were derived from the conceptual contents of their items. Factors explained $51.5 \%$ of variance.

Table 2. Results of confirmatory factor analyzes based on structures proposed by different authors and the structure found in this study

\begin{tabular}{|l|l|l|l|l|l|l|l|l|}
\hline Variables & Chi-square/df & $p$-value & RMSEA $^{\mathrm{a}}$ & $\mathrm{SRMR}^{\mathrm{b}}$ & $\mathrm{CFI}^{\mathrm{c}}$ & $\mathrm{GFI}^{\mathrm{d}}$ & $\mathrm{NFI}^{\mathrm{e}}$ & $\mathrm{IFI}^{\mathrm{f}}$ \\
\hline Janson (33) & 6.96 & $<0.05$ & 0.12 & 0.095 & 0.88 & 0.67 & 0.86 & 0.88 \\
\hline Gartus (32) & 5.31 & $<0.05$ & 0.10 & 0.085 & 0.91 & 0.79 & 0.89 & 0.91 \\
\hline Korukcu (29) & 5.38 & $<0.05$ & 0.11 & 0.087 & 0.91 & 0.73 & 0.89 & 0.91 \\
\hline Wijma (18) & 8.95 & $<0.05$ & 0.14 & 0.11 & 0.86 & 0.60 & 0.87 & 0.86 \\
\hline This study & 2.93 & $<0.05$ & 0.075 & 0.078 & 0.95 & 0.79 & 0.93 & 0.95 \\
\hline
\end{tabular}

a: root mean square error of approximation; b: standardized root mean square residual; c: comparative fit index; $d$ : goodness of fit index; e: normed fit index; f: incremental fit index

Table 3. Farsi W-DEQ (version A) six factors and factor loadings

\begin{tabular}{|l|l|l|l|l|l|l|l|}
\hline Item number & Items & 1 & 2 & 3 & 4 & 5 & 6 \\
\hline 13 & Not content & 0.847 & - & - & - & - & - \\
\hline 10 & Not independent & 0.814 & - & - & - & - & - \\
\hline 9 & Not protected & 0.774 & - & - & - & - & - \\
\hline 5 & Not confident & 0.732 & - & - & - & - & - \\
\hline 14 & Not proud & 0.629 & -0.313 & - & - & - & - \\
\hline 17 & Not relaxed & 0.558 & - & - & 0.509 & - & - \\
\hline 18 & Not happy & 0.552 & - & - & - & - & - \\
\hline 23 & Not reassured & 0.498 & - & - & - & - & - \\
\hline 22 & Not self-confidence & 0.420 & - & - & - & - & - \\
\hline 4 & Not strong & 0.411 & - & - & - & - & - \\
\hline 28 & Not joyful & - & 1.028 & - & - & - & - \\
\hline 21 & Not eager to bear child & - & 0.909 & - & - & - & - \\
\hline 29 & Not natural & - & 0.719 & - & - & - & - \\
\hline 30 & Not happen as expected & - & 0.639 & - & - & - & - \\
\hline 15 & Left alone & - & - & 0.719 & - & - & - \\
\hline 11 & Miserable & - & - & 0.627 & - & - & - \\
\hline 8 & Weak & - & - & 0.584 & 0.327 & - & - \\
\hline 7 & Abandoned & - & - & 0.537 & - & - & - \\
\hline 3 & Lonely & - & - & 0.536 & - & - & - \\
\hline 2 & Terrifying & - & - & 0.469 & - & - & - \\
\hline 20 & Hopeless & - & - & 0.396 & - & - & - \\
\hline 31 & Dangerous & - & - & 0.311 & - & - & - \\
\hline 19 & Frightened & - & - & - & 0.712 & - & - \\
\hline 6 & Fearful & - & - & - & 0.708 & - & - \\
\hline 24 & Painful & - & - & - & 0.549 & - & - \\
\hline 16 & Not cold-blooded & 0.450 & - & - & 0.473 & - & - \\
\hline 12 & Nervous & - & - & - & 0.431 & - & - \\
\hline 32 & Child will die & - & - & - & - & 0.964 & - \\
\hline 33 & Child will be hurt & - & - & - & - & 0.739 & - \\
\hline 27 & Lose control & - & - & - & - & - & 0.717 \\
\hline 25 & Act awfully & - & - & - & - & - & 0.662 \\
\hline 26 & Not let body to control & - & 0.410 & - & - & - & 0.421 \\
\hline Eigen value & & 10.1 & 3.4 & 2.1 & 1.6 & 1.3 & 1.2 \\
\hline Variance\% & & 30.7 & 10.3 & 6.3 & 4.9 & 3.8 & 3.7 \\
\hline & & & - & - & - & - \\
\hline
\end{tabular}

Method: principal axis factoring; method of rotation: promax; Factors' name (1. Lack of self-efficacy; 2. Lack of positive anticipation; 3 . Loneliness; 4 . Fear; 5 . Concerns for the child; 6 , concerns about losing control) 


\subsection{Reliability and validity}

\subsubsection{Reliability}

Table 4 shows Cronbach's alpha coefficients for the six subscales of the Farsi WDE-Q (versions A \& B).

3.3.2. Convergent validity

Convergent validity was investigated by calculating the correlation coefficient between the Farsi W-DEQ (version

A) scores and CAQ scores. It was 0.54 (Table 5).

\subsubsection{Concurrent validity}

Concurrent validity was investigated by the correlation coefficients between the Farsi W-DEQ (version A) scores, STAI-state, and STAI-Trait scores. They were 0.47 and 0.52 , respectively, indicating moderate relationships $(\mathrm{p}<0.001)$. Also, the Farsi WDE-Q (version B) correlated with EPSD at expected level (Table 5).

3.3.4. Discriminant validity

Discriminant validity was examined by comparing prenatal and postnatal childbirth fear in primiparas and multiparas. In Table 6, mean scores of the Farsi W-DEQ (version B) based on parity are presented. Although the Farsi W-DEQ version B could differentiate well between primiparous and multiparas, the Farsi W-DEQ version A could not distinguish between the two groups (Table 6).

\subsubsection{Predictive Validity}

Predictive validity was examined by comparing prenatal and postnatal childbirth fear in pregnant women who tended to have a Cesarean and those who preferred vaginal birth. Women who tended to have a Cesarean in antepartum or preferred cesarean for their next pregnancies in postpartum had higher mean scores on the Farsi WDEQ versions A \& B respectively than those who did not $(\mathrm{p}<0.001)$ (Table 6).

Table 4. Alpha Cronbach's coefficients of the Farsi W-DEQ (versions A \& B)

\begin{tabular}{|l|l|l|}
\hline \multirow{2}{*}{ Subscales } & Pregnancy (version A) & Postpartum (version B) \\
\cline { 2 - 3 } & Total (400) & Total (320) \\
\hline Lack of self-efficacy (10 items) & 0.894 & 0.911 \\
\hline Lack of positive anticipation (4 items) & 0.858 & 0.805 \\
\hline Loneliness (8 items) & 0.809 & 0.731 \\
\hline Fear (5 items) & 0.767 & 0.799 \\
\hline Concerns for the child (2 items) & 0.840 & 0.869 \\
\hline Concerns about losing control (3 items) & 0.696 & 0.633 \\
\hline Total & 0.914 & 0.919 \\
\hline
\end{tabular}

Table 5. Correlation matrix of the subscales of the Farsi W-DEQ †, CAQ $\ddagger$, and STAI§

\begin{tabular}{|l|l|l|l|l|l|l|l|l|}
\hline & & 1 & 2 & 3 & 4 & 5 & 6 & 7 \\
\hline 1 & Farsi W-DEQ (version A) & 1 & & & & & & \\
\hline 2 & Lack of self-efficacy & $0.90^{* * *}$ & 1 & & & & & \\
\hline 3 & Loneliness & $0.81^{* * *}$ & $0.62^{* * *}$ & 1 & & & & \\
\hline 4 & Lack of positive anticipation & $0.53^{* * *}$ & $0.44^{* * *}$ & $0.29^{* *}$ & 1 & & & \\
\hline 5 & Fear & $0.62^{* * *}$ & $0.48^{* * *}$ & $0.56^{* * *}$ & 0.04 & 1 & & \\
\hline 6 & Loss of control & $0.62^{* * *}$ & $0.44^{* * *}$ & $0.46^{* * *}$ & $0.35^{* * *}$ & $0.31^{* * *}$ & 1 & \\
\hline 7 & Concerns for the child & $0.39^{* * *}$ & $0.29^{* * *}$ & $0.12^{*}$ & $0.15^{* *}$ & $0.17^{* *}$ & $0.15^{* *}$ & 1 \\
\hline 8 & CAQ & $0.54^{* * *}$ & $0.47^{* * *}$ & $0.46^{* * *}$ & $0.13^{* *}$ & $0.46^{* * *}$ & $0.32^{* * *}$ & $0.25^{* *}$ \\
\hline 9 & State-STAI anxiety & $0.47^{* * *}$ & $0.45^{* * *}$ & $0.35^{* * *}$ & $0.18^{* *}$ & $0.37^{* * *}$ & $0.26^{* *}$ & $0.21^{* *}$ \\
\hline 10 & Trait-STAI anxiety & $0.52^{* * *}$ & $0.49^{* * *}$ & $0.42^{* * *}$ & $0.18^{* *}$ & $0.42^{* * *}$ & $0.30^{* * *}$ & $0.18^{* *}$ \\
\hline 1 & Farsi W-DEQ (version B) & 1 & & & & & & \\
\hline 2 & Lack of self-efficacy & $0.90^{* * *}$ & 1 & & & & & \\
\hline 3 & Loneliness & $0.84^{* * *}$ & $0.62^{* * *}$ & 1 & & & & \\
\hline 4 & Lack of positive anticipation & $0.56^{* * *}$ & $0.45^{* * *}$ & $0.31^{* *}$ & 1 & & & \\
\hline 5 & Fear & $0.72^{* * *}$ & $0.58^{* * *}$ & $0.68^{* * *}$ & 0.08 & 1 & & \\
\hline 6 & Loss of control & $0.60^{* * *}$ & $0.40^{* * *}$ & $0.49^{* * *}$ & $0.47^{* * *}$ & $0.26^{* *}$ & 1 & \\
\hline 7 & Concerns for the child & $0.42^{* * *}$ & $0.32^{* * *}$ & $0.17^{* *}$ & $0.19^{* *}$ & $0.23^{* *}$ & $0.23^{* *}$ & 1 \\
\hline 8 & EPDS£ & $0.48^{* * *}$ & $0.45^{* * *}$ & $0.40^{* * *}$ & $0.19^{* *}$ & $0.36^{* *}$ & $0.26^{* *}$ & $0.22^{* *}$ \\
\hline
\end{tabular}

${ }^{*} p<0.05,{ }^{* *} p<0.01,{ }^{* * *} p<0.001, \dagger$ Wijma Delivery Expectancy Questionnaire, $\$$ Childbirth Attitude Questionnaire, $\S$ State-Trait Anxiety Inventory, £ Edinburgh Postpartum

Depression Scale 
http://www.ephysician.ir

Table 6. Means of Farsi W-DEQ (version A and B) scores based on request for cesarean and childbirth attitudes questionnaire

\begin{tabular}{|l|l|l|l|l|}
\hline Scale & & $n(\%)$ & W-DEQ (version A) & $p$-value \\
\hline CAQ score $\dagger$ & $<37 \ddagger$ & $178(45)$ & $56.8 \pm 23.7$ & $<0.001^{* * *}$ \\
\cline { 2 - 5 } & $37 \leq$ & $217(55)$ & $76.2 \pm 20.4$ & \\
\hline \multirow{2}{*}{ Request for Cesarean } & Yes & $64(16)$ & $78.9 \pm 25.1$ & $<0.001^{* * *}$ \\
\cline { 2 - 5 } & No & $333(84)$ & $65.2 \pm 22.5$ & \\
\hline \multirow{2}{*}{ Parity } & & & W-DEQ (version B) & \\
\hline Preferred delivery mode for next pregnancy & Primiparas & $189(59)$ & $68.0 \pm 27.3$ & $0.032^{*}$ \\
\cline { 2 - 5 } & Multiparas & $131(41)$ & $61.9 \pm 22.8$ & \\
\cline { 2 - 5 } & Cesarean & $90(28)$ & $82.4 \pm 22.9$ & $<0.001^{* * *}$ \\
\hline & Vaginal delivery & $228(72)$ & $58.8 \pm 23.6$ & \\
\hline
\end{tabular}

$\dagger$ Childbirth Attitude Questionnaire score: $\$<37$ indicative of low childbirth fear

\section{Discussion}

This study was the first to translate and test the validity and reliability of the Farsi W-DEQ versions A \& B in pregnant and postpartum women in Iran. The W-DEQ assesses childbirth fears, which a mother may experience during pregnancy and postpartum. The scales can help in identifying women with a severe fear of childbirth during pregnancy and postpartum. Results showed that the both scales are reliable and valid instruments for measuring childbirth fear in Iranian women. Internal consistency of the both Farsi W-DEQ and their subscales were satisfactory, which is in harmony with previous studies $(18,28-31,33)$. Because the alpha coefficient is affected by the length of the scale (36), it is higher than 0.90 for the first subscales (self-efficacy) and scales as a whole. This phenomenon was seen in the mentioned studies, too $(18,28-31,33)$. The EFA could identify six factors. The six factors were lack of self-efficacy, lack of positive anticipation, fear, loneliness, concerns for the child, and concerns about losing control (32). Korukcu also proposed a six-factor model for version B, including concerns about labor pain, lack of positive behaviors, loneliness, lack of positive feelings, concerns about childbirth, and concerns about the baby (28). The Japanese version presented a four-factor structure, which included fear, lack of positive anticipation, isolation, and riskiness (30) and which were the same as the factor structure found by Janson (33). Results of the Croatian W-DEQ (version A) have shown that one-factor solution produced acceptable fit indices (31). Although the scales were examined in different populations, no similar structure was found, indicating the necessary of more validation studies on the scales. Regarding convergent validity, it was expected that the correlation coefficient between the scores of the Farsi W-DEQ version A and CAQ be strong $(r>0.7)$ whereas it was moderate $(r=0.54)$, indicating that the version A measures different aspects of childbirth fear. Concurrent validity was confirmed by the moderate correlations between the scores of the both Farsi W-DEQ versions and STAI, which meant that the Farsi W-DEQ measured something different from the STAI, the scales for measuring anxiety. In other words, mothers with childbirth fear may not have an anxious personality or may not be in a state anxiety. In Wijma's study, the correlations between the scores of the version A and Trait Anxiety Inventory were .54 and .55 for nulliparous and multiparas, respectively. The corresponding figures for version B were 0.48 and 0.44 (18). Jansen's study also found moderate correlations between the scores of the W-DEQ and STAI, too (33). Considering the predictive validity of the Farsi WDE-Q, a higher mean score of the Farsi W-DEQ versions A \& B was found in women who preferred Cesarean for current or next pregnancy than women who preferred vaginal birth, which is in agreement with the results of previous studies $(10,12)$. The Farsi W-DEQ version B could also discriminate between nulliparas and multiparas. These findings harmonized with previous research $(6,42,43)$. In Gartus's study, the mean scores of three subscales of the W-DEQ were higher in nulliparous than multiparas (32). This study has strong and weak points. The strong point of the study was that it was composed of two phases, which enabled us to find the scale structure in the antenatal phase and subsequently examine the structure in the postnatal phase. The second strong point of the study is that the Farsi W-DEQ version B was tested in women who gave birth vaginally and had a live experience of vaginal birth. The first weak point of the study is that the Farsi W-DEQ version A was tested in women who planned for vaginal birth. It is probable that women who planned for Cesarean had a higher childbirth fear. However, the proportion of this group is low because obstetricians are not allowed to do a cesarean elective due to maternal request. The second weak point of the study is that the convergent validity of the version B was not examined because there was no other validated questionnaire in Farsi to assess childbirth fear during postpartum. 


\section{Conclusions}

The present study confirmed the content validity, reliability, and construct validity of the Farsi W-DEQ versions A $\&$ B. The scales consisted of six factors, which are not completely replicated the factors found in previous studies. The scales can be used for understanding childbirth fear in prenatal and postpartum women in future researches. Because the Farsi W-DEQ version A was validated in pregnant women in the third trimester of pregnancy, it is recommended that the scale be validated in pregnant women regardless of their gestational age.

\section{Acknowledgments:}

The researcher would like to thank the research committee of Sabzevar University of Medical Sciences, which approved and financed this work, the members of expert panel who kindly helped in the process of content validity of the scales, and all midwives who collected the data.

\section{Conflict of Interest:}

There is no conflict of interest to be declared.

\section{References:}

1) Roland-Price A, Chamberlain Z. Management of tocophobic women. In: Arulkumaran S, editor. Preconceptional Medicine Paula and David Bloomer. 281-8.

2) Eriksson C, Jansson L, Hamberg K. Women's experiences of intense fear related to childbirth investigated in Swedish qualitative study. Midwifery. 2006; 22(3): 240-8. doi: 10.1016/j.midw.2005.10.002. PMID: 16603282 .

3) Lowe NK. Self efficacy for labour and childbirth fears in nulliparous pregnant women. J psychosom obstet Gynecol. 2000; 21(4): 219 -24. doi: 210.3109/01674820009085591. PMID: 11191169.

4) Manizheh P, Leila P. Perceived Environmental Stressors and Pain Perception During Labor Among Primiparous and Multiparous Women. J Reprod Infertil. 2009; 10(3): 217-23. PMID: 23926472, PMCID: PMC3719331.

5) Areskog B, Uddenberg N, Kjessler B. Postnatal emotional balance in women with or without antenatal fear of childbirth. J Psychosom Res. 1984; 28(3): 213-20. doi: 10.1016/0022-3999(84)90022-9. PMID: 6545359.

6) Saisto T, Salmela-Aro K, Nurmi JE, Halmesmäki E. Psychosocial characteristics of women and their partners fearing vaginal childbirth. BJOG. 2001; 108(5): 492-8. doi: 10.1111/j.471-0528.2001.00122.x. PMID: 11368135.

7) Saisto T, Salmela-Aro K, Nurmi JE, Könönen T, Halmesmäki E. A randomized controlled trial of intervention in fear of childbirth. Obstet Gynecol. 2001; 98(5pt1): 820-6. PMID: 11704175.

8) Bakshi A, Mehta A, Mehta A, Sharma B. Tokophobia: Fear of Pregnancy and Childbirth. The Internet Journal of Gynecology and Obstetrics. 2008; 10(1).

9) Adams SS, Eberhard-Gran M, Eskild A. Fear of childbirth and duration of labour: a study of 2206 women with intended vaginal delivery. BJOG. 2012; 119(10): 1238-46. doi: 10.111/j.471-0528.2012.03433.x. PMID: 22734617.

10) Nieminen K, Stephansson O, Ryding EL. Women's fear of childbirth and preference for cesarean section-a cross-sectional study at various stages of pregnancy in Sweden. Acta Obstet Gynecol Scand. 2009; 88(7): 807-13. doi: 10.1080/00016340902998436. PMID: 19488882.

11) Ryding EL, Wijma B, Wijma K, Rydhström H. Fear of childbirth during pregnancy may increase the risk of emergency caesarean section. Acta Obstet Gynecol Scand. 1998; 77(5): 542-7. doi: 10.1080/j.6000412.1998.770512.x. PMID: 9654177.

12) Nerum H, Halvorsen L, Sorlie T, Oian P. Maternal request for cesarean section due to fear of birth: can it be changed through crisis-oriented counseling? Birth. 2006; 33(3): 221-8. doi: 10.1111/j.523536X.2006.00107.x. PMID: 16948722.

13) Gamble JA, Creedy DK. Women's request for a cesarean section: a critique of the literature. Birth. 2000; 27(4): 256-63. doi: 10.1046/j.523-536x.2000.00256.x. PMID: 11251511.

14) Hildingsson I, Rådestad I, Rubertsson C, Waldenström U. Few women wish to be delivered by caesarean section. BJOG. 2002; 109(6): 618-23. doi: 10.1111/j.471-0528.2002.01393.x. PMID: 12118637.

15) Hofberg K, Ward MR. Fear of pregnancy and childbirth. Postgrad Med J. 2003; 79(935): 505-10. doi: 10.1136/pmj.79.935.505. PMID: 13679545, PMCID: PMC1742837. 
16) Gibbons L, Belizán JM, Lauer JA, Betrán P, Merialdi M, Althabe F. The Global Numbers and Costs of Additionally Needed and Unnecessary Caesarean Sections Performed per Year: Overuse as a Barrier to Universal Coverage. World Health Report. Background Paper, No 30. Geneva: WHO. 2010.

17) Alimohamadian M, Shariat M, Mahmoodi M, Ramezanzadeh F. The influence of maternal request on the elective caesarean section rate in maternity hospitals in Tehran, Iran. Payesh. 2003; 2: 133-9.

18) Wijma K, Wijma B, Zar M. Psychometric aspects of the W-DEQ: a new questionnaire for the measurement of fear of childbirth. J Psychosom Obstet Gynecol. 1998; 19(2): 84-97. doi: 10.3109/01674829809048501. PMID: 9638601.

19) Harman $P$, editor. Fear of Childbirth and Related Incidence of Complications in Labor and Delivery. The 33rd Annual Meeting of the American College Nurse-Midwives; 1988; Detroit, MI.

20) Khorsandi M, Ghofranipour F, Hidarnia A, Faghihzadeh S, Vafaei M, Rousta F, et al. The effect of childbirth preparation classes on childbirth fear and normal delivery among primiparous women. Journal of Arak University of Medical Sciences. 2008; 11(3): 29-36.

21) Spielberger C, Gorsuch R, Lushene R, Vagg P, Jacobs G. Manual for the State-Trait Anxiety Inventory. Palo Alto, CA: Consulting Psychologists Press; Inc. 1983.

22) Barnes LLB, Harp D, Jung WS. Reliability generalization of scores on the Spielberger State-Trait Anxiety Inventory. Educational and Psychological Measurement. 2002; 62(4): 603-18. doi: $10.1177 / 0013164402062004005$.

23) Mahram B. Validity of Spielberger state-trait anxiety inventory (STAI) in Mashhad city. Tehran: Allameh Tabatabaei University. 1993.

24) Cox JL, Holden JM, Sagovsky R. Detection of postnatal depression. Development of the 10-item Edinburgh Postnatal Depression Scale. Br J psychiatry. 1987; 150: 782-6. doi: 10.1192/bjp.150.6.782. PMID: 3651732.

25) Montazeri A, Torkan B, Omidvari S. The Edinburgh Postnatal Depression Scale (EPDS): translation and validation study of the Iranian version. BMC psychiatry. 2007; 7: 11. doi: 10.1186/1471-244X-7-11. PMID: 17408479, PMCID: PMC1854900.

26) Wijma K, Alehagen S, Wijma B. Development of the Delivery Fear scale. J Psychosom Obstet Gynaecol. 2002; 23(2): 97-107. doi: 10.3109/01674820209042791. PMID: 12189903.

27) Fenarol V, Saita E. Fear of childbirth: a contribution to the validation of the italian version of the wijma delivery expectancy/experience questionnaire (WDEQ). TPM-Testing, Psychometrics, Methodology in Applied Psychology. 2013; 20(2). doi: 10.4473/TPM20.2.3.

28) Korukcu O, Bulut O, Kukulu K. Psychometric Evaluation of the Wijma Delivery Expectancy/Experience Questionnaire Version B. Health Care Women Int. 2016; 37(5): 550-67. doi: 10.1080/07399332.2014.943838. PMID: 25119342.

29) Korukcu O, Kukulu K, Firat MZ. The reliability and validity of the Turkish version of the Wijma Delivery Expectancy/Experience Questionnaire (W-DEQ) with pregnant women. J Psychiatr Ment Health Nurs. 2012; 19(3): 193-202. doi: 10.1111/j.1365-2850.2011.01694.x. PMID: 22260727.

30) Takegata M, Haruna M, Matsuzaki M, Shiraishi M, Murayama R, Okano T, et al. Translation and validation of the Japanese version of the Wijma Delivery Expectancy/Experience Questionnaire version A. Nurs Health Sci. 2013; 15(3): 326-32. doi: 10.1111/nhs.12036. PMID: 23425355.

31) Žigić L, Nakić S, Jokić-Begić N, editors. The validation of the Croatian version of the Wijma Delivery Expectancy/Experience Questionnaire. XVIII Dani psihologije u Zadru- Symposium on Reproductive Mental Health; 2012; Zadar, Hrvatska. 2012.

32) Garthus-Niegel S, Storksen HT, Torgersen L, Von Soest T, Eberhard-Gran M. The Wijma Delivery Expectancy/Experience Questionnaire: a factor analytic study. J psychosom obstet gynaecol. 2011; 32(3): 160-3. doi: 10.3109/0167482x.2011.573110. PMID: 21506662.

33) Johnson R, Slade P. Does fear of childbirth during pregnancy predict emergency caesarean section? BJOG. 2002; 109(11): 1213-21. doi: 10.1046/j.1471-0528.2002.01351.x. PMID: 12452457.

34) Lawshe C. A quantitative approach to content validity. Pers Psychol. 1975; 28: 563-75. doi: 10.1111/j.1744-6570.1975.tb01393.x.

35) Polit D, Beck C. Nursing Research: Principles and Methods (Nursing Research: Principles \& Practice). 46th ed. Philadelphia: Lippincott. 2004; 416-45

36) Streiner D. Starting at the Beginning: An Introduction to Coefficient Alpha and Internal Consistency. J Pers Assess. 2003; 80(1): 99-103. doi: 10.1207/S15327752JPA8001-18. PMID: 12584072.

37) Kline RB. Principles and Practice of Structural Equation Modeling, Third Edition (Methodology in the Social Sciences). New York: The Guilford Press. 2005. 
38) Tabachnick BG, Fidell LS. Using Multivariate Statistics. Boston: Allyn and Bacon. 2001.

39) Hu LT, Bentler PM, editors. Evaluating model fit. CA: Thousand Oaks: Sage. 1995.

40) Bentler PM, Bonett DG. Significance tests and goodness of fit in the analysis of covariance structures. Psychol Bull. 1980; 88(3): 588-606. doi: 10.1037/0033-2909.88.3.588.

41) Hu LT, Bentler PM. Cutoff criteria for fit indexes in covariance structure analysis: Conventional criteria versus new alternatives. Struct Equ Modeling. 1999; 6(1): 1-55. doi: 10.1080/10705519909540118.

42) Spice K, Jones SL, Hadjistavropoulos HD, Kowalyk K, Stewart SH. Prenatal fear of childbirth and anxiety sensitivity. J psychosom obstet gynaecol. 2009; 30(3): 168-74. doi: 10.1080/01674820902950538. PMID: 19591052.

43) Sluijs AM, Cleiren MP, Scherjon SA, Wijma K. No relationship between fear of childbirth and pregnancy/delivery-outcome in a low-risk Dutch pregnancy cohort delivering at home or in hospital. J psychosom obstet gynaecol. 2012; 33(3): 99-105. doi: 10.3109/0167482x.2012.685905. PMID: 22621317. 